\title{
Estratégias para sustentar o interesse em realizar residência médica em Medicina de Família e Comunidade durante tempos de pandemia de COVID-19 no contexto brasileiro
}

Strategies to support interest in doing medical residency in Family Medicine during times of the COVID-19 pandemic in the Brazilian context

\section{Estrategias para mantener el interés en realizar la residencia médica en Medicina Familiar y Comunitaria en tiempos de la pandemia COVID-19 en el contexto brasileño}

\author{
Rafael Fernandes de Almeida ${ }^{1,2}$ (D), Bruna Lasserré Nunes Coêlho² 이 \\ ${ }^{1}$ Escola Superior de Ciências da Saúde - Brasília (DF), Brasil. \\ 2Universidade de Brasília, Faculdade de Medicina - Brasília (DF), Brasil.
}

\section{Resumo}

A residência médica é considerada o padrão-ouro na formação de especialistas em Medicina de Família e Comunidade. Há uma alta demanda por profissionais adequadamente qualificados nessa área no contexto brasileiro. No entanto, essa residência ainda se mostra pouco atrativa para boa parte dos egressos de Medicina, fato revelado pelas inúmeras vagas ociosas e altas taxas de desistência a despeito de seriadas tentativas de torná-la mais motivante para o candidato. A pandemia intensificou ainda mais esse desinteresse e há sinais de que ela persistirá em 2021. Assim, torna-se necessário e urgente buscar novas estratégias. Entre as alternativas que podem combater esse desânimo estão a reestruturação de ambientes de ensino virtual e a redistribuição da carga horária dos residentes.

Palavras-chave: Internato e residência; Motivação; Pandemias.

*Como citar: Almeida RF, Coêlho BLN. Estratégias para sustentar o interesse em realizar residência médica em Medicina de Família e Comunidade durante tempos de pandemia de COVID-19 no contexto brasileiro. Rev Bras Med Fam Comunidade. 2021;16(43):2817. https://doi.org/10.5712/rbmfc16(43)2817

\section{Autor correspondente:}

Rafael Fernandes de Almeida

E-mail: rafael.fdealmeida@gmail.com

Fonte de financiamento:

não se aplica

Parecer CEP:

não se aplica

Procedência:

não encomendado.

Avaliação por pares:

externa.

Recebido em: 01/12/2020.

Aprovado em: 06/08/2021. 


\begin{abstract}
Medical residency is considered the gold standard in the training of specialists in Family Medicine. There is a high demand for suitably qualified professionals in this area in the Brazilian context. However, this residency is still unattractive to most medical graduates, a fact revealed by the countless vacant vacancies and high dropout rates despite serious attempts to make it more motivating for the candidate. The pandemic has further intensified this lack of interest and there are signs that it will persist in 2021. Thus, it is necessary and urgent to seek new strategies. Among the alternatives that can combat this discouragement are the restructuring of virtual teaching environments and the redistribution of residents' workload.
\end{abstract}

Keywords: Internship and Residence; Motivation; Pandemics.

\title{
Resumen
}

La residencia médica se considera el estándar de oro en la formación de especialistas en Medicina Familiar y Comunitaria. Existe una gran demanda de profesionales debidamente calificados en esta área en el contexto brasileño. Sin embargo, esta residencia sigue siendo poco atractiva para la mayoría de los graduados de medicina, un hecho revelado por las innumerables vacantes y las altas tasas de deserción a pesar de los serios intentos de que sea más motivadora para el candidato. La pandemia ha intensificado aún más este desinterés y hay indicios de que persistirá en 2021. Por ello, es necesario y urgente buscar nuevas estrategias. Entre las alternativas que pueden combatir este desánimo se encuentran la reestructuración de los entornos de enseñanza virtual y la redistribución de la carga de trabajo de los residentes.

Palabras clave: Internado y residencia; Motivación; Pandemias.

\section{INTRODUÇÃO}

Atualmente a residência médica é entendida como o método padrão-ouro para a formação de médicos de família e comunidade. ${ }^{1}$ No entanto, a despeito das diversas tentativas de torná-la atraente para os egressos das faculdades de Medicina, ainda se observa um grande número de vagas ociosas nos Programas de Residência Médica em Medicina de Família e Comunidade (PRMMFC), além de altas taxas de desistencia. ${ }^{2}$ Esse cenário tornou-se ainda mais crítico perante a pandemia. ${ }^{3}$ Ainda que cientes das potenciais dificuldades na jornada de ser um médico de família e comunidade no Brasil, os novos residentes enfrentaram uma situação de calamidade pública que desafiou suas motivações de seguir na especialidade. ${ }^{4}$ Depararam-se com um cenário político desestimulante, alta pressão assistencial e uma pequena oportunidade de desenvolver competências próprias ao médico de família e comunidade durante seus anos de residência. Os largos sorrisos e roupas despojadas, que construíam sua identidade única e manifestavam sua diversidade, ficaram também escondidos nas máscaras e aventais brutalmente iguais. E, para muitos, essa somatória tornou-se insustentável.

Seguir uma carreira na Medicina de Família e Comunidade (MFC) é indubitavelmente inspirador, mas também significa abdicar de uma série de privilégios sociais de que a classe médica ainda goza, mesmo diante das mudanças de paradigmas do século XXI. ${ }^{5,6}$ Esse fato representa fator importante na decisão de um estudante de Medicina sobre qual especialidade seguir. Trilhar a MFC é ser contracorrente. É questionar o modelo hospitalocêntrico e médico hegemônico, a assistência patriarcal, a medicina não baseada em evidências, a iatrogenia sistematizada, a fragmentação do cuidado, a visão reducionista biológica, a patologização e a medicalização dos problemas diários, a desigualdade social, a indústria farmacêutica e a mercantilização da saúde. Ao mesmo tempo, é suportar o baixo reconhecimento profissional por parte de colegas médicos especialistas focais e até mesmo dos usuários; é trabalhar diariamente com alto grau de incertezas e de responsabilidades; é recusar parcialmente o status social e financeiro do médico; é muitas vezes sentir as consequências de uma gestão de saúde insuficiente; é 
lidar com violência urbana e com alta vulnerabilidade social; é estar disposto a ouvir mesmo quando não se é ouvido; é lutar contra o apelo midiático bilionário e seus produtos na saúde da população; é saber que outros médicos de família e profissionais da Atenção Primária à Saúde (APS) estão em depressão e que a própria especialidade lidera rankings de burn-out. ${ }^{7}$

Enquanto muitos programas oferecem complementação monetária à bolsa de residência médica, fato esse que contribui para conquistar médicos recém-formados, ainda há aqueles que não dispõem desse atrativo. Em geral, quem opta pelo caminho sem tais incentivos é motivado por um ideário de ensino e de preceptoria consagradamente qualificados ou uma estrutura pedagógica mais sólida. Mas se, em tempos de COVID-19, a maior porcentagem dos atendimentos volta-se a sintomáticos respiratórios, por que submeter-se a um processo seletivo e, ainda, permanecer em programas sem complementação se há outras vias que podem trazer uma experiência similar, com maior grau de autonomia e que culminam também na possibilidade de obtenção de título de médico de família e comunidade (como o programa Mais Médicos), enquanto se usufrui de maior retorno financeiro?

Verdadeiramente, é natural, e talvez até esperada, a baixa procura por tais programas de residência (sejam eles com ou sem complementação), bem como o desejo de abandoná-los em um segundo momento. Muitos dos que optam por esse caminho justificam-se com base na conveniência; na avaliação de que ainda compensa o aprendizado assistido independentemente dos entraves; na aspiração de conseguir o título de especialista de forma mais rápida; na possibilidade de realizar uma próxima especialização ou residência (como, por exemplo, área de atuação em Medicina Paliativa ou subespecialidade em Medicina Rural e de áreas isoladas); ou mesmo na utilização da bonificação de $10 \%$ para concorrer novamente a programas de residência médica para outras especialidades que lhes pareçam mais interessantes ou menos estafantes. Seja qual for a razão, torna-se necessário ampliar o debate e repensar o próprio molde da residência médica: como ela pode tornar-se mais desejável, principalmente em tempos de pandemia? As projeções atuais apontam para a manutenção da infecção pelo novo SARS-CoV-2, ${ }^{8}$ ainda mais quando se leva em consideração a atual política nacional de enfrentamento do vírus. Sendo assim, é imperativo pôr em pauta essa discussão no momento atual para que sejam pensadas e implementadas novas estratégias no futuro próximo.

Em consonância com essa teoria, julga-se necessário enumerar intervenções praticadas por algumas instituições nesse contexto (ainda que transitoriamente), que pareceram surtir efeito positivo na retenção de residentes durante o ano de 2020. São citadas aqui algumas dessas instituições e seus respectivos méritos com o intuito único de demonstrar a viabilidade dessas estratégias, com a ressalva de que procedimentos semelhantes podem, até mesmo, ter-se dado em outros programas. Ressalta-se que a falta de uma avaliação objetiva dos impactos de cada intervenção não deve ser responsável por limitar a geração de ideias para motivar a formação de novos médicos de família e comunidade por meio da residência médica.

A título de ilustração, houve programas, como o do Grupo Hospitalar Conceição (GHC) em Porto Alegre, que reconfiguraram sua carga horária no início da pandemia para que parte dos residentes estivesse em seus domicílios para a realização de atividades de ensino remotas a fim de reduzir a aglomeração de residentes nas respectivas Unidades Básicas de Saúde, mantendo, ainda assim, a carga horária exigida. Tal proposta tinha como fundamento a questão sanitária, mas reproduzia também um modelo de ensino que provê melhor produtividade ao respeitar a necessidade de descanso mental do estudante. .11 $^{9-1}$

Como esperado, medidas como essa impactaram positivamente a satisfação dos médicos residentes. Estes não apenas se sentiram mais amparados e seguros, mas também mais propensos a dedicar-se ao estudo teórico de temas gerais de MFC em vez de somente repetirem exaustivamente a aplicação 
dos protocolos de atendimento a casos de COVID-19, nos quais o método clínico centrado na pessoa se desenhava de forma abstrata demais em meio à estranheza dos equipamentos de proteção individual. Esse tempo dedicado a atividades remotas possibilitava aos residentes a realização de uma série de cursos on-line relacionados à prática clínica característica do médico de família e comunidade, bem como tinha papel terapêutico na redução da sobrecarga gerada pelos incontáveis atendimentos de sintomáticos respiratórios em vigência da pandemia. Nessa lógica de formação a distância, listam-se aqui alguns dos vários cursos utilizados pelos residentes e voltados à APS ofertados gratuitamente na plataforma Arouca pela Universidade Aberta do Sistema Único de Saúde (UNA-SUS), os quais podem integrar parcialmente a grade curricular: Abordagem Domiciliar em Situações Clínicas Comuns em Idosos, Dermatologia na Atenção Básica, Prevenção ao Suicídio, Saúde da Mulher, entre outros.

Faz sentido o sucesso dessa mudança levando-se em consideração a faixa etária média dos atuais residentes e o perfil geracional dos millenials (Geração Y), os quais tendem a desafiar a hierarquia do status quo, são abertos e adaptáveis às mudanças, possuem conhecimento intuitivo de tecnologia e apresentam estilos de aprendizagem mais virtuais, bem como a tendência de orientar-se para uma vida mais centrada no foro pessoal em detrimento da carreira profissional. ${ }^{12}$ Um PRMMFC genuinamente interessado na formação acadêmica do residente deve também ser centrado nele, estando apto a mudar sua estrutura conforme as necessidades de uma nova geração a fim de ser mais exitoso. Ainda assim, não se deve supor que a adoção de tal estratégia de forma isolada e pontual possa ser suficiente e capaz de prevenir totalmente ou anular o sentimento de inadequação em meio a uma situação desta magnitude, e deve-se lembrar que outros vários fatores (alguns alheios até à própria pandemia) têm papel central na decisão final do residente.

Entre outras sugestões aparentemente bem-sucedidas, destaca-se a formação de uma frente de ensino a distância minuciosamente planejada, como foi o caso do PRMMFC da Escola Superior de Ciências da Saúde (ESCS) em Brasília. Nesse programa, a grade teórica reorganizou-se em semanas tão logo se iniciaram as primeiras restrições sanitárias, e o currículo foi assim transposto para a esfera virtual de forma rápida e satisfatória. Convocam-se aqui os programas nos quais há preceptores com maior familiaridade em tecnologia de informação para que se crie desde cedo um ambiente virtual para a efetivação da programação teórica. Em contraste, naqueles que tardam a executar esse mesmo espaço, corre-se o risco de gerar uma sensação nos residentes de maior distanciamento com a formação de habilidades específicas da MFC, as quais têm papel fundamental na criação de sentido e identidade do pós-graduando. A utilização de recursos audiovisuais como vídeos, filmes e séries televisivas nesse mesmo modelo de ensino torna-se extremamente vantajosa para um grupo de médicos que possui perfil mais informal, pois consegue captar mais facilmente a sua atenção e despertar seu interesse, concomitantemente trazendo leveza para o estudo teórico diante da carga já pesada dos tempos atuais. Esses instrumentos didáticos já eram populares em muitos programas pelo Brasil, mas devem ganhar ainda mais relevância com o prolongamento da pandemia.

Retoma-se também a importância da existência de grupos Balint em plataformas digitais para os residentes, esses que foram especialmente afetados por um menor senso de pertencimento e de grupo decorrente, em parte, da impossibilidade de aglomerações físicas. Neste momento, os grupos Balint ${ }^{13}$ atuam de forma extraordinária, possibilitando tanto o compartilhamento de experiências singulares da relação médico-paciente quanto a interação entre os residentes. Tais momentos proporcionam maior desenvolvimento profissional e pessoal individual e coletivamente, auxiliando os residentes a entender melhor o impacto de suas personalidades nos diferentes ambientes de consultório. A operacionalização 
dessa ferramenta deu-se de forma exemplar na residência da Secretaria Municipal de Saúde de Florianópolis, ocorrendo quinzenalmente e revelando assim a potencialidade desse espaço, ainda que em outro formato.

A seleção dos temas das aulas pode, enquanto contempla o currículo baseado em competências, dar preferência temporal às identificadas como mais intrigantes pelos próprios residentes. Isto é, o simples remanejamento da ordem dos temas pode facilitar o engajamento dos residentes no programa. Se, por exemplo, for detectado que a turma tem uma demanda maior por aprender sobre Prevenção Quaternária ou Saúde Planetária, há de se adiantar a abordagem de tais temas para os primeiros encontros como forma de cativar esse grupo específico. Essa liberdade traduziu-se em maior entusiasmo no cenário do GHC, palco de aulas inaugurais como Violência Doméstica e Resiliência.

O uso do canal virtual para a comunicação também permite que o palestrante não esteja nem mesmo na cidade onde ocorre a residência médica. Assim sendo, é de interesse da coordenação do programa que busque convidar diferentes profissionais gabaritados para participar de aulas a fim de aparar lacunas de conhecimento e funcionar como alavanca na otimização do ensino. Essa ferramenta consegue também democratizar e nivelar a qualidade do ensino na proporção em que torna mais viável a inclusão de PRMMFC menores e incipientes em uma grade curricular mais ampla, construída conjuntamente com outros PRMMFC já mais robustos e experientes. Percebeu-se essa troca em nível intramunicipal, como, por exemplo, entre o programa do Hospital de Clínicas de Porto Alegre e o GHC em aulas de metodologia científica, epidemiologia e gerenciamento, e também entre o Hospital Universitário de Brasília e a ESCS em temas clínicos. Deve-se ter como plano abranger essa tática em nível interestadual, com consistência.

É evidente que se perde muito do poder da troca de conhecimentos na ausência de encontros presenciais. Justamente por isso, é essencial repensar a educação médica diante dessa conjuntura. Entende-se como obsoleta a expectativa de que o residente se transforme integralmente para adequar-se às necessidades da instituição ou de que ele seja unicamente o agente responsável por satisfazer suas demandas de conhecimento. A confiança nessa ilusão terá como consequência a manutenção, se não o aumento, do número de vagas ociosas nos PRMMFC.

Assim, é necessário que esses programas se mobilizem e concretizem mudanças. Se optarem por resignar-se e seguirem em inércia, é fatal a precarização da formação do médico de família e comunidade no Brasil. O antídoto é a inovação.

\section{CONFLITO DE INTERESSES}

Nada a declarar.

\section{CONTRIBUIÇÕES DOS AUTORES}

RFA: Conceituação, Metodologia, Escrita - Primeira Redação, Escrita - Revisão e Edição. BC: Metodologia, Escrita - Revisão e Edição.

\section{REFERÊNCIAS}

1. Brasil. Ministério da Saúde. Lei 6.932, de 7 de julho de 1981. Dispõe sobre as atividades do médico residente e dá outras providências. Brasília: Presidência da República; 1981.

2. Scheffer M, Departamento de Medicina Preventiva da Faculdade de Medicina da USP, Conselho Regional de Medicina do Estado de São Paulo. Demografia Médica no Brasil 2015. São Paulo: Conselho Federal de Medicina; 2015. 
3. Sobrinho WP. Residentes do HC reclamam de exploração e formação prejudicada na pandemia [Internet]. 2020 [acessado em 20 nov. 2020]. Disponível em: https://noticias.uol.com.br/saude/ultimas-noticias/redacao/2020/08/10/residentes-do-hcreclamam-exploracao-e-formacao-prejudicada-na-pandemia.html

4. Hahn TW. Virtual noon conferences: providing resident education and wellness during the COVID-19 pandemic. PRiMER 2020;4:17. https://doi.org/10.22454/PRiMER.2020.364166

5. Ramos-Cerqueira ATA, Lima MCP. A formação da identidade do médico: implicações para o ensino de graduação em Medicina. Interface (Botucatu) 2002;6(11):107-16. https://doi.org/10.1590/S1414-32832002000200008

6. Cavalcante Neto PG, Lira GV, Miranda AS. Interesse dos estudantes pela medicina de família: estado da questão e agenda de pesquisa. Rev Bras Educ Med 2009;33(2):198-204. https://doi.org/10.1590/S0100-55022009000200006

7. Mello GA, Mattos ATR, Souto BGA, Fontanella BJB, Demarzo MMP. Médico de família: ser ou não ser? Dilemas envolvidos na escolha desta carreira. Rev Bras Educ Med 2009;33(3):464-71. https://doi.org/10.1590/S0100-55022009000300017

8. Scudellari M. How the pandemic might play out in 2021 and beyond. Nature 2020;584(7819):22-5. https://doi.org/10.1038/ d41586-020-02278-5

9. Martini S, Arfken CL, Balon R. Comparison of burnout among medical residents before and after the implementation of work hours limits. Acad Psychiatry 2006;30(4):352-5. https://doi.org/10.1176/appi.ap.30.4.352

10. Ogawa R, Seo E, Maeno T, Ito M, Sanuki M, Maeno T. The relationship between long working hours and depression among first-year residents in Japan. BMC Med Educ 2018;18(1):50. https://doi.org/10.1186/s12909-018-1171-9

11. Moeller A, Webber J, Epstein I. Resident duty hour modification affects perceptions in medical education, general wellness, and ability to provide patient care. BMC Med Educ 2016;16:175. https://doi.org/10.1186/s12909-016-0703-4

12. Louie M, Moulder JK, Wright K, Siedhoff M. Mentoring millennials in surgical education. Curr Opin Obstet Gynecol 2019;31(4):279-84. https://doi.org/10.1097/GCO.0000000000000546

13. Yazdankhahfard M, Haghani F, Omid A. The Balint group and its application in medical education: a systematic review. $J$ Educ Health Promot 2019;8:124. https://doi.org/10.4103/jehp.jehp_423_18 